\title{
A FORMAÇÃO DE PROFESSORES PARA A EDUCAÇÃO INCLUSIVA: UM OLHAR CRÍTICO
}

\author{
TEACHERSTRAINING FOR INCLUSIVE EDUCATION:
}

\author{
A CRITICAL VIEW
}

\author{
Adriana Fratoni dos Santos ${ }^{1}$ \\ Roberta Negrão de Araujo ${ }^{2}$
}

\begin{abstract}
Resumo
O presente estudo discute a formação inicial dos docentes que atuarão nos anos iniciais do ensino fundamental. Tem como objetivo geral analisar, no que tange à educação inclusiva, a estrutura do curso de Pedagogia. Assim, apresenta o percurso histórico do curso de Pedagogia, bem como os documentos legais sobre a educação inclusiva; discute a formação inicial diante da escola inclusiva e aponta a contribuição da Pedagogia Histórico-Crítica e da Psicologia Histórico-Cultural na formação de professores para ensinar alunos com deficiência. Para tanto recorreu-se à pesquisa bibliográfica, tomando como fonte as publicações na área. Como resultado evidenciou-se que houve uma mudança no percurso histórico do curso de Pedagogia no Brasil, ainda que sejam lentas na sua efetivação; quanto às políticas sobre a educação inclusiva são reconhecidos importantes avanços nos aspectos legais e educacionais; já em relação à formação de professores, esta deve capacitá-los para enfrentar tais desafios em sua carreira profissional.
\end{abstract}

Palavras-chave: Formação de Professores. Educação Inclusiva. Pedagogia Histórico-Crítica. Psicologia Histórico-Cultural.

\begin{abstract}
This study discusses the initial training of teachers who will work in the first years of elementary school. It has as general aim to analyze, in regard to inclusive education, the Pedagogy course structure. Thus, it presents the historical background of the Pedagogy course, as well as the legal documents about inclusive education; it discusses the initial training on the inclusive school and highlights the contribution of Historical-Critical Pedagogy and Historical-Cultural Psychology in the teacher training to teach students with disabilities. For this, was used the literatura research, taking as source publications in the area. As a result, it became clear that there was a change in the historical background of the Pedagogy course in Brazil, although they are slow in its effectiveness; as policies about inclusive education are recognized important advances in the legal and educational aspects;

\footnotetext{
${ }^{1}$ Graduada em pedagogia,Especialista em Educação Especial Inclusiva, ambos ofertado pelo Centro de Ciências Humanas e da Educação, da Universidade Estadual do Norte do Paraná - UENP, Campus de Cornélio Procópio. Especialização em Educação Infantil. Atualmente professora da Educação Básica da rede Municipal de Cornélio Procópio. Ênfase na área da Educação. Integrante do Grupo de Pesquisa em Educação (GEPEDUC) na linha de formação de professores. E-mail: fratonidri@hotmail.com

${ }^{2}$ Mestre em Educação pela Universidade Estadual de Londrina. Especialização em Orientação e Supervisão. Graduada em Licenciatura em Ciências, com Habilitação em Química. Professora da rede pública estadual Paraná - Colégio Estadual Cristo Rei - Ensino Normal/ Professora Assistente D - Colegiado de Pedagogia Universidade Estadual do Norte do Paraná/ Campus Cornélio Procópio. E-mail: robertanegrao@uenp.edu.br
} 
so, in relation to teacher training, this should enable them to confront these challenges in his professional career.

Keywords: Training of Teachers. Inclusive Education. Historical-Critical Pedagogy. Historical-Cultural Psychology.

\section{INTRODUÇÃO}

A formação inicial (graduação) é essencial na constituição do profissional da educação. $\mathrm{Na}$ atualidade, frente às diferenças, esta formação, em sua totalidade, deve dar conta dos desafios da inclusão do aluno com deficiência, transtornos globais do desenvolvimento e altas habilidades/superdotação (BRASIL/LDBEN 9394/96, art. 58). Nesta perspectiva, o curso de Pedagogia tem se preocupado com a questão da educação inclusiva. No entanto, evidenciamos que o referido curso apresenta limitações no que tange ao preparo do docente para atuar diretamente com alunos que necessitam de um atendimento educacional especializado, visto a abrangência e necessidade da educação inclusiva.

Assim, algumas inquietações surgiram a respeito da formação de professores para a educação inclusiva. Na busca de explicações surgiu o problema que norteou a presente pesquisa: De que forma o curso de formação de professores - Licenciatura em Pedagogia, ofertado pela Universidade Estadual do Norte do Paraná/Campus Cornélio Procópio - está organizado para atender a demanda da educação inclusiva?

Diante do problema, elencamos como objetivo geral: analisar a estrutura do curso de formação de professores, no âmbito da graduação, no que tange à educação inclusiva. Este foi detalhado em objetivos específicos, que serviram como tópicos para organização deste estudo. Assim, na primeira seção apresentamos o percurso histórico do curso de Pedagogia, como também os documentos legais sobre a educação inclusiva. Em seguida, discutimos a formação de professores, em nível de graduação, para atuar na escola inclusiva. Na terceira e última seção abordamos sobre a Pedagogia Histórico-Crítica e a Psicologia Histórico-Cultural, além de apresentar a contribuição destas perspectivas na formação de professores para ensinar alunos com deficiência.

Para a realização do estudo recorremos à pesquisa bibliográfica e documental. Nesta metodologia tomamos como fonte as publicações impressas e digitais, em forma de livros, periódicos, dissertações e teses, entre outros. 


\section{PERCURSO HISTÓRICO DO CURSO DE PEDAGOGIA}

O percurso histórico do curso de Pedagogia no Brasil justifica-se pela necessidade de analisar sua estrutura e organização para a formação do professor, sobretudo no que diz respeito à educação inclusiva. O referido curso, no Brasil, iniciou em 1939 com o Decreto Lei $n^{\circ}$. 1.190/39, definido como lugar de formação de "técnicos em educação", conferindo ao curso o "estudo da forma de ensinar".

De acordo com Saviani (2008), o Decreto organizou/estruturou o curso em quatro seções: filosofia, ciências, letras e pedagogia e uma seção especial de didática. Assim, o curso de Pedagogia originou com as seções de pedagogia e didática. E o modelo padrão consistia em duas modalidades: bacharelado com três anos de duração e licenciatura.

Inicialmente, oferecia o título de bacharel a quem cursasse três anos de estudos. Depois para obter o diploma de licenciatura era necessário cursar um ano de Didática, dando origem ao esquema " $3+1$ ", que permitia o pedagogo atuar como professor. A estrutura do curso só foi modificada com a aprovação da primeira Lei de Diretrizes e Bases da Educação Nacional (LDBEN) n.4024/61. Segundo Saviani (2008), a aprovação do Parecer no 252/69 do Conselho Federal de Educação resultou a Resolução no $2 / 69$, no qual foi fixado o mínimo de conteúdos e duração de quatro anos para o curso de Pedagogia.

Ao fazer referência ao currículo do curso, este era composto por uma parte comum e outra diversificada com habilitação em: Orientação Educacional, Administração Escolar, Supervisão Escolar e Inspeção Escolar, assim como de professor para o ensino normal. Com isso, havia a formação do generalista e do especialista no mesmo curso de graduação, assim como determinava o art. $1^{\circ}$ da resolução que

[...] a formação de professores para o ensino normal e de especialistas para as atividades de orientação, administração, supervisão e inspeção, no âmbito de escolas e sistemas escolares, será feita no curso de graduação em Pedagogia, de que resultará o grau de licenciado com modalidades diversas de habilitação (BRASIL/CFE no. 02/69).

Quanto a este currículo, a estrutura geral do curso vigorou até a aprovação da LDBEN n. 9394/96, sofrendo alterações posteriormente às novas Diretrizes Curriculares Nacionais (BRASIL/DCN, 2006).

A LDBEN n. 9394/96 apregoa, em seu art. 59, inciso III, que os professores devem ter capacitação adequada para o atendimento dos educandos com necessidades especiais. No entanto, evidenciamos um desafio no que tange à formação para este atendimento, já que para 
atuar junto aos alunos com necessidades especiais, tendo como intuito a inclusão destes há, ainda, muitos limites e dificuldades.

Segundo Saviani (2008, p.63), ’[...] a demora na definição das diretrizes curriculares do curso de pedagogia propiciou a crise do curso de pedagogia, já que estas só foram aprovadas em 2006". Foi com as DCN de 2006, que o curso tem como objetivo formar o pedagogo para atuar na Educação Infantil, nas séries iniciais do Ensino Fundamental, nos cursos de Ensino Médio - modalidade normal, e como Gestor nas áreas de Supervisão e Orientação Educacional em instituições escolares e não escolares.

Saviani (2008) ressalta que dificilmente as Diretrizes se distanciariam do que consta do documento aprovado, uma vez que o texto foi negociado pelo Conselho Nacional de Educação (CNE) com as entidades. O autor recorre a Libâneo (2007, p.94) para esclarecer sobre as imprecisões contidas no texto das Diretrizes Curriculares para o Curso de Pedagogia

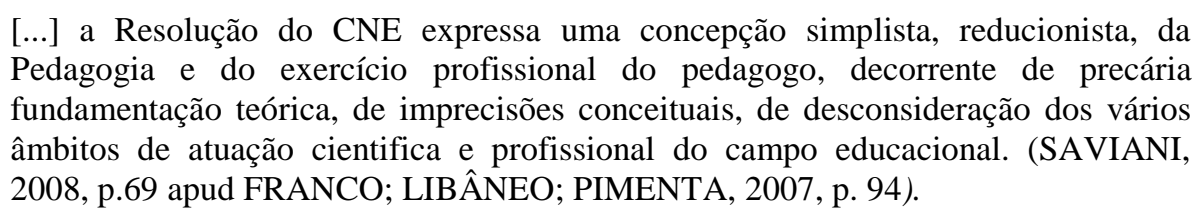

Evidenciamos, portanto, fragilidade na base teórica e conceitual, haja vista formar o profissional que atuará da educação infantil ao ensino médio e, ainda, como gestor em instituições escolares e não escolares. A atuação em outros espaços exige a compreensão de outra concepção de educação - a educação não formal - pautada em bases teóricas diferenciadas.

No que tange à modalidade em pauta, há que se considerar que o texto das DCN Pedagogia menciona apenas uma vez a educação especial. O art. $8^{\circ}$, inciso III, apregoa que os termos do projeto pedagógico das instituições de ensino superior, ao falar da experiência na modalidade de ensino, ficarão como atividades complementares sendo "opcionalmente, a educação de pessoas com necessidades especiais". Não aparece como estágio curricular a ser realizado ao longo do curso, garantindo aos graduandos experiência de exercício profissional contido no inciso IV.

É fato que os documentos oficiais contemplam o atendimento aos alunos com necessidades educacionais. Destes, destacamos a Constituição Federal (CF) de 1988, em seu art. 208; Lei $n^{\circ}$ 7.853/89; Lei $n^{\circ}$ 8.069/90; LDBEN nº 9394/96; Diretrizes Nacionais para Educação Especial na educação Básica (2001) entre outros. 
Ao aluno com necessidades educacionais especiais (NEE) é garantido o seu ingresso na educação, preferencialmente na rede regular ou na modalidade especifica, como assegura o inciso I do art. 59 da LDBEN no 9394/96, “os sistemas de ensino assegurarão [...] currículos, métodos, técnicas, recursos educativos e organização específicos, para atender às suas necessidades". Logo, o professor deve utilizar metodologias, recursos e procedimentos diferenciados, sempre que necessários. Mas, acima de tudo, ofertar uma educação com qualidade social que priorize o conhecimento científico e sistematizado a todos.

Neste contexto, a formação de professores deve ter como princípio o desenvolvimento do pensamento teórico crítico, dando as condições para que o processo aconteça como alerta Saviani

[...] que a prática será tanto mais coerente e consistente, será tanto mais qualitativa, será tanto mais desenvolvida quanto mais consistente e desenvolvida for a teoria que a embasa, e que uma prática será transformada à medida que exista uma elaboração teórica que justifique a necessidade da sua transformação e que proponha as formas da transformação, estamos pensando a prática a partir da teoria (SAVIANI, 2008, p.107).

Há uma visão antagônica à perspectiva teórico-pedagógica adotada por muitas instituições de ensino e outras vezes pelos órgãos que representam a educação nacional. Ao considerar essas barreiras entre a teoria e a prática é fundamental buscar a importância da seriedade da escola no trabalho educativo que realiza, considerando o papel do saber sistematizado, a partir do qual se define a especificidade da educação escolar (SAVIANI, 2008).

\section{EDUCAÇÃO INCLUSIVA: O QUE DIZ A LEI?}

As conquistas no mundo demandaram tempo para sua efetivação. Com a educação inclusiva não foi diferente, seu movimento também foi e, ainda é, lento. Podemos registrar que as políticas de inclusão de alunos que apresentam necessidades educativas especiais fundamentam-se em fatores mais abarcantes do que somente as leis. Uma das questões, por exemplo, é trabalhar no sentido da homogeneização, fundamentado em práticas pedagógicas que não remetem à educação inclusiva, que visa o trabalho com a diversidade e a diferença. Todavia, ainda que lento, houve importantes avanços nos aspectos legais e educacionais em prol dos direitos humanos. Alguns destes acontecimentos são importantes ressaltar. 
Com início em 1948, a Declaração Universal dos Direitos Humanos oportunizou o direito de todos à educação pública e gratuita. Foi em 1961, com a LDBEN n. 4.024, que a Educação Especial foi contemplada, pela primeira vez, na legislação nacional. A referida lei aponta, no art.88, que “A educação de excepcionais ${ }^{3}$ deve no que for possível, enquadrar-se no sistema geral de educação, a fim de integrá-los na comunidade”. Posteriormente, a lei no 5.692/71 alterou a LDBEN nº4024/61 ao definir 'tratamento especial'.

Art. $9^{\circ}$ Os alunos que apresentem deficiências físicas ou mentais, os que se encontrem em atraso considerável quanto à idade regular de matrícula e os superdotados deverão receber tratamento especial, de acordo com as normas fixadas pelos competentes Conselhos de Educação.

Em 1988, com a promulgação da sétima Constituição Federal Brasileira, foi garantido o atendimento educacional de pessoas que apresentassem necessidades educacionais especiais, reafirmando o direito de todos à educação, esse atendimento será segundo a constituição, oferecida preferencialmente na rede regular de ensino.

\begin{abstract}
Art. $3^{\circ}$, inciso IV - promover o bem de todos, sem preconceitos de origem, raça, sexo, cor, idade e quaisquer outras formas de discriminação;

[...] Art. 205. A educação, direito de todos e dever do Estado e da família, será promovida e incentivada com a colaboração da sociedade, visando ao pleno desenvolvimento da pessoa, seu preparo para o exercício da cidadania e sua qualificação para o trabalho;

[...] Art. 206 [...] I - igualdade de condições para o acesso e permanência na escola;

[...] Art. 208. O dever do Estado com a educação será efetivado mediante a garantia de [...] III - atendimento educacional especializado aos portadores ${ }^{4}$ de deficiência, preferencialmente na rede regular de ensino (BRASIL/CF, 1988).
\end{abstract}

$\mathrm{O}$ atendimento educacional especializado foi garantido, proporcionando melhor qualidade no atendimento e na garantia de sua oferta.

Em 1990, a Conferência Mundial de Educação para Todos, realizada em Jomtien/ Tailândia, discutiu a oferta de educação para todos e a previu como direito fundamental. A conferência contou com a presença de representantes de 155 governos de diferentes países, teve como meta principal a revitalização do compromisso mundial de educar todos os cidadãos do planeta.

Em 1994, com a Declaração de Salamanca (UNESCO), foi realizada uma Conferência Mundial sobre Necessidades Educativas Especiais: Acesso e Qualidade, na qual dirigentes de mais de 80 países se reuniram na Espanha e assinaram a Declaração, reconhecido como um

\footnotetext{
${ }^{3}$ Excepcionais - Termo utilizado na época que se criou a Lei.

${ }^{4}$ Portadores - Termo utilizado na época em que se criou a referida lei.
} 
dos mais importantes documentos de compromisso de garantias de direitos educacionais, este documento apregoa as escolas regulares inclusivas como o meio mais eficaz de combate à discriminação.

A LDBEN n. 9394/96 ajustou-se à legislação federal, e reafirmou que a educação das pessoas com necessidades especiais deve dar-se, preferencialmente, na rede regular de ensino. Na referida lei, todo o capítulo V é dedicado à Educação Especial. Assim, como modalidade, garantiu-se o atendimento desde a educação infantil até o ensino superior.

Em 1999, a Declaração da Guatemala - Convenção Interamericana para a Eliminação de Todas as Formas de Discriminação contra as Pessoas Portadoras de Deficiência - reafirma "que as pessoas portadoras de deficiência têm os mesmos direitos humanos e liberdades fundamentais, inclusive o direito de não ser submetidas à discriminação com base na deficiência".

Em 2001, por meio da Resolução do CNE/CNB nº. 02, de 11 de fevereiro, foi publicada as Diretrizes Nacionais para a Educação Especial na Educação Básica. Tais diretrizes visam ampliar o caráter da educação especial

Art. $2^{\circ}$ Os sistemas de ensino devem matricular todos os alunos, cabendo às escolas organizar-se para o atendimento aos educandos com necessidades educacionais especiais, assegurando as condições necessárias para uma educação de qualidade para todos $(\mathrm{CNE} / \mathrm{CNB}, 2001)$.

Com base nos documentos, ao analisar as políticas educacionais, evidenciamos que estas contemplam a educação inclusiva de qualidade. Contudo, há limitações e entraves nas leis aprovadas, como consequência das discussões que permeiam o contexto educacional brasileiro.

\section{A FORMAÇÃO DE PROFESSORES PARA ATUAR COM ALUNOS COM DEFICIÊNCIA: A EXPERIÊNCIA DA UNIVERSIDADE ESTADUAL DO NORTE DO PARANÁ}

Em 2006, após a aprovação das DCN - Pedagogia, o curso ofertado na Universidade Estadual do Norte do Paraná (UENP)/Campus Cornélio Procópio (CCP) passou por alterações em seu Projeto Pedagógico de Curso (PPC) e, consequentemente, em sua grade curricular.

O ano de 2012 marcou o início da implantação deste novo PPC. Vale ressaltar que o curso começou a evidenciar a questão da educação inclusiva mudando, mesmo que timidamente, a organização do quadro de disciplinas, voltados à formação para esta área. $\mathrm{O}$ 
curso, na atualidade, tem em sua carga horária 3364 horas. Destas, somente três disciplinas, totalizando 216 horas, focam a inclusão e contemplam a temática diversidade, em seu amplo leque de discussões.

No primeiro ano não há disciplina sobre educação especial e inclusão. No segundo ano há a oferta da disciplina de Língua Brasileira de Sinais, que na matriz anterior era trabalhada no quarto ano. Sua ementa aborda a introdução aos aspectos clínicos, educacional e sócio antropológicos da surdez. A Língua de Sinais Brasileira (Libras): características básicas da fonologia. Noções básicas de léxico, de morfologia e de sintaxe com apoio de recursos audiovisuais; Noções de variação. Praticar Libras: desenvolver a expressão visual-espacial. De 72 horas, 60 são dedicadas à base teórica.

No terceiro ano trabalha-se com a disciplina "Politicas, Educação e Diversidade", trabalhando as políticas públicas e programas relacionados à diversidade: educação do campo, educação em direitos humanos, educação escolar indígena, educação para a diversidade étnico-racial, gênero e pessoas com deficiência. Da carga horária de 72 horas, 60 são dedicadas à base teórica.

Já no quarto ano, a disciplina "Fundamentos Teóricos e Políticos da Educação Especial" foca aspectos históricos da Educação Especial. Bases teóricas e legais da educação inclusiva. Caracterização das deficiências. Educação Inclusiva e o atendimento às necessidades educacionais especiais do aluno com deficiência nos diferentes níveis de ensino. Legislação e Políticas Públicas para a Educação Especial Inclusiva no Brasil. Da carga horária de 72 horas, 52 são dedicadas à base teórica.

Em comparação à grade anterior, do PPC de 2006, a nova grade curricular (2012) teve a inclusão da disciplina "Fundamentos Teóricos e Políticos da Educação Especial” e, ainda, apresenta já no segundo ano do curso a disciplina "Libras". Considerando sua abrangência e complexidade, o curso muitas vezes não dá conta de oportunizar o conhecimento de todas as áreas. Por outro lado, tem a responsabilidade de instrumentalizar o acadêmico, proporcionando-lhe a atuação profissional futura. Desta forma, o fio condutor na formação inicial de professores, deve primar pelas necessidades contemporâneas e, diante disso, melhor qualificar o corpo docente.

Segundo Rodrigues (2008, p.8), o que se espera do professor hoje é que seu conhecimento vá “[...] desde o conhecimento científico o que ensina à sua aplicação psicopedagógica, bem como em metodologias de ensino, de animação de grupos, atenção à diversidade". Verificamos que as modificações na grade curricular do curso de Pedagogia, a 
universidade pesquisada e de outras em geral estão tentando durante o tempo de sua implantação atender a diversidade para a formação do pedagogo, mas que ainda não estão suficientemente preparados para assumir uma educação inclusiva de qualidade no sentido de promover a aprendizagem no aluno com necessidades educacionais especiais. Segundo o autor, o que precisa ser feito em relação à formação do professor para um atendimento melhor é que durante a sua formação deve

Proporcionar ao professor um conjunto de experiências que não só lhe revelem novas perspectivas teóricas sobre o conhecimento (perspectiva acadêmica), mas que também o impliquem em situações empíricas que lhe permitam aplicar estes conhecimentos num contexto real (perspectiva profissional). (RODRIGUES, 2008, p.8).

O autor remete à prática docente, o desafio de relacionar a teoria e conciliá-la as novas necessidades que a educação necessita.

Contudo, a respeito da formação do professor durante a graduação, verificamos que algumas ações na sociedade ajudariam a envolver mais o processo de inclusão como aponta Toledo

\begin{abstract}
A necessidade da formação do professor para a diversidade existente em nossas escolas pode ser um fator desencadeante de algumas ações, tais como: parceria entre as secretarias de Educação e as universidades, por meio de cursos de aperfeiçoamentos, especialização, assessoramento, desenvolvimento de pesquisa das universidades em escolas públicas, as quais, ao desenvolverem seu trabalho, acabam interferindo favoravelmente no processo de inclusão, promovendo a reflexão e o crescimento dos envolvidos (TOLEDO, 2011, p.35).
\end{abstract}

Para tanto, é importante que todos os envolvidos no processo educacional articulem, junto à comunidade acadêmica, a melhor forma de possibilitar a capacitação para o atendimento à diversidade.

Mazzeu (2011, p. 154), ao analisar a formação de professores na perspectiva dos pressupostos epistemológicos que fundamentam os documentos oficiais, comenta que o Relatório denominado Jacques Delors (2002), “[...] endossa as orientações do Banco Mundial quanto à formação inicial e continuada. Destaca a formação por competências [...] tendo como norte a reflexão sobre a prática" (p. 154). Diante dessa nova visão da formação dos professores destaca a formação do professor "pautado no domínio dos conhecimentos teóricocientífico e pedagógico seria inadequado". Para a sua superação sugere-se o modelo "pautado pela formação reflexiva e pela competência" (p.154).

Ao tomar como foco os Referenciais para a formação de professores, Mazzeu (2011, p.158) destaca que a "[...] formação reflexiva deve ser incorporada à formação do professor de modo que potencialize a ação e a reflexão, tidas como necessárias ao desenvolvimento de 
uma prática educativa competente e problematizadora". Assim, chama atenção para a formação de professores pautada na formação continuada, na qual a prática docente deve estar em constante reflexão e atualização dos conhecimentos científicos pedagógicos. Nesse sentido, aderimos ao pensamento de Rodrigues, quando diz que

\begin{abstract}
A formação de professores encontra- se, hoje, em profundas mudanças tanto do ponto de vista de conceitos e valores como de práticas. A este fato, não é estranho que as competências que se esperam que o professor domine se revelem cada vez mais complexas e diversificadas (RODRIGUES, 2008, p. 8)
\end{abstract}

Há a necessidade, portanto, do professor adotar múltiplas ações diversificadas em seu trabalho em sala de aula, para tanto a formação deve prepará-lo para enfrentar tais desafios em sua carreira e atuação profissional.

\title{
4 CONTRIBUIÇÕES DA PEDAgOGIA HISTÓRICO-CRÍTICA E DA PSICOLOGIA HISTÓRICO-CULTURAL NA FORMAÇÃO DE PROFESSORES
}

Para a compreensão do processo de formação de professores tomamos como base a contribuição da Pedagogia Histórico-Crítica e da Psicologia Histórico-Cultural e seus postulados a respeito da educação, que o "[...] saber que diretamente interessa à educação é aquele que emerge como resultado do processo de aprendizagem, como resultado do trabalho educativo" (SAVIANI, 2008, p.7). Nesse sentido a educação deve ser um ato de produzir diretamente um conhecimento no homem.

Nagel (2007) concorda com tal pensamento afirmando que "são os atos educativos que levam a pensar o homem como um ser ativo, com intencionalidade".

Pensando os atos educativos a ser desenvolvidos em nossos alunos, é que devemos questionar como estão sendo organizados os cursos de formação de professores para atender a demanda de uma educação inclusiva. Afirmando essa proposição, Nagel (2007) aponta os baixos índices apresentados pelo Brasil no teste de desempenho aplicado pelo Programa Nacional de Avaliação dos Estudantes (Pisa).

No intuito de afirmar a contribuição da Pedagogia Histórico-Crítica e seu papel na formação de professores, bem como a sua relação com a educação escolar, Saviani diz que ela implica

a) Identificação das formas mais desenvolvidas em que se expressa o saber objetivo produzido historicamente, reconhecendo as condições de sua produção e compreendendo as suas principais manifestações, bem como as tendências atuais de transformação. 
b) Conversão do saber objetivo em saber escolar, de modo que se torne assimilável pelos alunos no espaço e tempo escolares.

c) Provimento dos meios necessários para que os alunos não apenas assimilem o saber objetivo enquanto resultado, mas aprendam o processo de sua produção, bem como as tendências de sua transformação (SAVIANI, 2008, p. 9)

A Pedagogia Histórico-Crítica contribui na formação de professores no que tange ao saber, pois este é "objeto específico do trabalho escolar" (SAVIANI, 2008, p. 9). Tal perspectiva tem servido de referência para a organização de propostas para o ensino dos conteúdos escolares e para a orientação da formação de professores, de maneira que eles possam perceber nesta perspectiva que a educação é um processo intencional e que visa o conhecimento sistematizado. Os passos sugeridos pelo autor (1984, p. 71) são: a prática social, a problematização, a instrumentalização, a catarse e a prática social.

Segundo Barroco (2011, p. 179), isso aconteceria "num exercício da lógica dialética e numa visão histórica. Nela, a escola defendida pode fazer enfrentamentos a partir da prática social, a ela ascendendo, teorizando-a e desvendando as suas múltiplas determinações." Os subsídios apresentados pela perspectiva da Pedagogia Histórico-Crítica vêm, portanto, contribuir com o trabalho educacional desenvolvidos de forma geral no sistema de ensino.

No que tange ao reconhecimento da educação especial, este aconteceu de forma paulatina, como aponta Barroco

Muitas coisas mudaram até se chegar à idéia, presente nos dias de hoje, de que a deficiência não retira do homem sua possibilidade de humanização, é que não é, em si, uma doença, mas uma condição [talvez advinda de uma doença] com a qual a pessoa convive, quase sempre, por toda a sua vida (2007, p.119).

A educação deve fazer parte da aprendizagem do deficiente e não constituir-se num impedimento para seu processo de desenvolvimento. Segundo Barroco (2007, apud LEONTIEV, 1978, p. 272), a educação é, antes de mais nada, um processo de humanização.

As aquisições do desenvolvimento histórico das aptidões humanas não são simplesmente dadas aos homens nos fenômenos objetivos da cultura material e espiritual que os encarnam, mas são aí apenas postas. Para se apropriar destes resultados, para fazer deles as suas aptidões, ' os órgãos da sua individualidade', a criança, o ser humano, deve entrar em relação com os fenômenos do mundo circundante através de outros homens, isto é, num processo de comunicação entre eles. Assim, a criança aprende a atividade adequada. Pela sua função, este processo é, portando, um processo de educação (BARROCO, 2007, p.117).

Isto acontece pelo processo de educação. Assim, é pela humanização, que vamos adquirindo novos conhecimentos. Nesse sentido, os estudos vygotskyanos apresentaram, por meio da Psicologia Histórico-Cultural, o reconhecimento da aprendizagem no desenvolvimento do ser humano, mesmo com condições atípicas. Seguindo este pensamento é 
que Barroco (2011, p. 172), aponta a defesa de Vygotsky em falar de compensações e superações na visão do materialismo histórico-dialético para a educação especial ou a defectologia como ele chamava, "[...] ao seu ver, deveria oferecer uma escola auxiliar ou escola especial forte para quem se apresentava como fraco".

Na perspectiva vygotskyana, quando se tem um impedimento no fator biológico, deve ser desenvolvido o talento cultural. O que reforça a questão de que o homem se humaniza nas relações sociais em que está inserido, ou seja, o homem vai aprender a ser humano por meio da mediação com os outros humanos inseridos no ambiente e contexto em que vive.

Segundo Eidt e Ferracioli (2007, p.107), a partir da compreensão da Psicologia Histórico-Cultural, o ser humano aprende a tornar-se humano. Contudo, as pessoas que apresentam necessidades educativas especiais podem e têm potencialidades para se desenvolver. Neste sentido, a criança ao nascer vai precisar de um comportamento humano, de referências humanas para desenvolver-se, que irá caracterizá-lo como sujeito humanizado. Evidenciando que a cultura, na qual o sujeito está inserido, torna-se fundamental neste processo de humanização. Visto que "A humanização do homem não é uma decorrência biológica, mas conseqüência de um longo processo de investimento no aprendizado da criança pequena, processo que se dá no interior do grupo social" (EIDT; FERRACIOLI, 2007, p.107).

Tal afirmação significa que a criança aprende na relação com os adultos e no contexto em que vive, passando muitas vezes a entender o uso de objetos como instrumento para atingir e desenvolver novas funções, desenvolvendo as Funções Psicológicas Superiores (FPS). Portanto, deve-se levar em conta de que apenas o fator biológico não significa que não haverá desenvolvimento, pois, segundo a Psicologia Histórico-cultural, devemos entender como uma transformação, ou seja, diante do processo cultural que possa possibilitar desenvolver funções cada vez mais complexas, pois

\footnotetext{
As funções psicológicas superiores (FPS), tais como a atenção, memória, imaginação, pensamento e linguagem são organizadas em sistemas funcionais, cuja finalidade é organizar adequadamente a vida mental de um individuo em seu meio (VERONESE; DAMASCENO; FERNANDES, 2005, p. 538).
}

Deste modo, as FPS afirmam-se ao longo do desenvolvimento do sujeito na qual faz parte a interação entre sujeito e a sociedade, a cultura e a história de vida de cada um. Essa interação, além de necessária, é fundamental para o desenvolvimento da aprendizagem e sua inserção na sociedade. Com isso não temos um resultado pronto e acabado, pois a aprendizagem se faz por meio de um processo. Não podemos atribuir exclusivamente aos 
nossos alunos com necessidades educativas especiais limitações e dificuldades apresentadas, mas sim tornar necessário rever os aspectos que permeiam o processo no qual estão inseridos.

O trabalho do professor consiste em atuar no papel de ensinar, no desenvolvimento de estratégias, deixando o fato em si da deficiência para sim verificar as consequências sociais desta.

\begin{abstract}
A educação da criança com diferentes defeitos deve basear-se no fato de que simultaneamente com o defeito estão dadas também as tendências psicológicas de uma direção oposta; estão dadas as possibilidades de compensação para vencer o defeito e de que precisam, ente essas possibilidades se apresentam em primeiro plano no desenvolvimento da criança e devem ser incluídas no processo educacional como sua força motriz. Estruturar todo processo educativo segundo a linha das tendências naturais a supercompensação significa não atenuar as dificuldades que surgem no defeito. [...], mas tensionar todas as forças para sua compensação (MATOS, 2011, apud VIGOTSKI, 1997, p.32).
\end{abstract}

Diante disso, percebemos que a deficiência em si não é algo que impede todo o desenvolvimento humano, já que o que implica em tal condição são as diferentes formas de trabalho pedagógico que oportunizam a aprendizagem. A criança com necessidades educativas especiais devem ter acesso aos mesmos conteúdos que as outras, porém este deve dar-se por formas diferentes de trabalho.

\title{
CONSIDERAÇÕES FINAIS
}

Identificamos que as condições históricas a respeito da educação inclusiva criaram circunstâncias nas quais foram dadas atenção à escolarização da pessoa com deficiência. Nesse sentido, o foco no tema formação de professores suscitou o questionamento que norteou a pesquisa: De que forma o curso de formação de professores - Pedagogia está organizado para atender a demanda de uma educação inclusiva?

Para respondê-lo, por meio da pesquisa bibliográfica, evidenciamos que a formação de professores e a organização da grade curricular do curso de Pedagogia, em relação à educação inclusiva, têm fundamental importância no atendimento das pessoas com necessidades educativas especiais. Defendemos, portanto, que a Pedagogia Histórico-Crítica e a Psicologia Histórico-cultural contribuem a respeito da formação de professores já que os profissionais da educação têm papel importante no desenvolvimento da aprendizagem do sujeito, pois estas vertentes teóricas dimensionam o papel fundamental que a educação possui na formação do ser humano, bem como subsidia a base teórico-pedagógica dos profissionais da educação. 
Dentre os resultados obtidos com esta pesquisa frente aos objetivos específicos, apontamos que no percurso histórico do curso de Pedagogia no Brasil houve mudanças: de lugar de formação de "técnicos em educação", ao "estudo da forma de ensinar", que consistia em duas modalidades, a de bacharelado e de licenciatura. Que posteriormente deu origem ao esquema " $3+1$ ”, revelado no texto. Assim, verificamos que o curso de Pedagogia firmou-se a partir da aprovação das Diretrizes Curriculares Nacionais para o Curso de Graduação em Pedagogia (2006).

Conforme apontamos na segunda seção, as conquistas educacionais demandaram tempo para sua efetivação. Com a educação inclusiva não foi diferente, seu movimento também foi e, ainda é, lento. Porém, ainda que lento, houve importantes avanços nos aspectos legais e educacionais, em prol dos direitos humanos.

Primeiramente foi entendido que os alunos com deficiência não deveriam ficar segregados, mas que deveriam integrar-se em novos ambientes. Assim, tinham que se adaptar às exigências da escola na qual fariam parte. Hoje, finalmente, evidenciou-se que é a escola que deve se adaptar às necessidades dos alunos, buscando atender com qualidade toda a diversidade existente, ou seja, que estes alunos tenham acesso à educação inclusiva, a que todos têm direito.

Em seguida tomamos como base para discussão a formação de professores em um curso de Pedagogia de uma universidade na região norte do Paraná. Tal contexto possibilitou identificar a situação inicial do curso e como se apresentou após a implantação das Diretrizes Curriculares Nacionais para o Curso de Graduação em Pedagogia em 2006. Pois, diante as múltiplas ações diversificadas que o professor deve ter para seu trabalho em sala de aula, deve haver uma formação de professores que o prepare para receber tais desafios em sua carreira e atuação profissional.

Corroboramos com a compreensão do processo de formação de professores tendo como base a contribuição da Pedagogia Histórico-Crítica e da Psicologia Histórico-Cultural a respeito da educação. Desta forma, com base nas referências consultadas, os cursos de formação de professores, bem como o professor, ao atuar na dimensão da inclusão, devem estar cientes das múltiplas situações e desenvolvimento do seu trabalho que, por muitas vezes, preparado e esclarecido de sua função educacional, pode por meio da escola, proporcionar a criança contato com os conhecimentos sistematizados e construídos historicamente pela humanidade. É por meio das atividades e conteúdos escolares que o acesso e apropriação da cultura decorrerão, impulsionando o desenvolvimento das Funções Psicológicas Superiores. 


\section{REFERÊNCIAS}

BARROCO, S. M. S. A educação especial do novo homem soviético e a psicologia de L. S. Vigotski: implicações e contribuições para a psicologia e a educação atuais. Tese (Doutorado) - Programa de Pós-Graduação em Educação Escolar, Universidade Paulista, Araraquara. 2007.

Pedagogia histórico-crítica, psicologia histórico-cultural e educação especial: em defesa do desenvolvimento da pessoa com e sem deficiência In: MARSIGLIA, Ana Carolina Galvão (Org.). Pedagogia Histórico-Crítica: 30 anos.Campinas: Autores Associados, 2011. (Coleção Memória da Educação).

BRASIL. Lei $n^{\circ}$ 9.394, de 20 de Dezembro de 1996. Disponível em:

<http://www.planalto.gov.br/ccivil_03/Leis/L9394.htm>. Acesso em: 30 jul de 2014

. Decreto lei $N^{o} .1 .190$ - de 4 de abril de 1939. Disponível em: <http://www.planalto.gov.br/CCIVIL_03/Decreto-Lei/1937-1946/Del1190.htm>Acesso em 10 de ago de 2014

. Ministério da Educação. Lei de diretrizes e bases da educação nacional (Lei $\mathrm{n}^{\circ}$ 4.024/61), 1961.

Resolução CNE/CP $n^{o} \mathbf{1}$, de 15 de maio de 2006. Institui Diretrizes

Curriculares Nacionais para o Curso de Graduação em Pedagogia, Licenciatura. Disponível em: 〈http:// portal.mec.gov.br/cne/arquivos/pdf/rcp01_06.pdf〉. Acesso em: 30 jul de 2014.

Lei $n^{\circ} 5.692$, de 11 de agosto de 1971. Fixa Diretrizes e Bases para o ensino de $1^{\circ} \mathrm{e}$

$2^{\circ}$ graus, e dá outras providências. Disponível em:

< http://www.planalto.gov.br/ccivil_03/leis/L5692impressao.htm>. Acesso em: 30 jul 2014. (revogada pela Lei $\mathrm{N}^{\circ}$ 9.394/96)

Lei $n^{\circ} 7.853$, de 24 de outubro de 1989. Dispõe sobre o apoio às pessoas portadoras de deficiência, sua integração social, sobre a Coordenadoria Nacional para Integração da Pessoa Portadora de Deficiência. Disponível em: <

http://portal.mec.gov.br/seesp/arquivos/pdf/res2_b.pdf 1_03/leis/17853.htm> Acesso em: 17 de ago de 2014.

Lei $n^{\circ}$ 8.069, de 13 de julho de 1990. Dispõe sobre o Estatuto da Criança e do Adolescente e dá outras providências. Disponível em:

<http://www.planalto.gov.br/ccivil_03/leis/18069.htm> Acesso em: 17 de ago de 2014.

Resolução $C N E / C E B n^{\circ}$ 2, de 11 de fevereiro de 2001. Institui Diretrizes Nacionais

para a Educação Especial na Educação Básica. Disponível em:<

http://portal.mec.gov.br/seesp/arquivos/pdf/res2_b.pdf>. Acesso em: 17 de ago de 2014.

Assembléia Nacional Constituinte. Constituição da República Federativa do Brasil.

Brasília: Senado Federal/ Secretaria Especial de Editorações e Publicações, 1988. 
EIDT, Nadia Mara; FERRACIOLI, Marcelo Ubiali. O ensino escolar e o desenvolvimento da atenção e da vontade: superando a concepção organicista do Transtorno de Déficit de Atenção e Hiperatividade (TDAH). In: ARCE, Alessandra; MARTINS, Lígia Márcia (Org). Quem tem medo de ensinar na Educação Infantil. Campinas: Alínea, 2007.

MATOS, Neide da Silveira Duarte de. A educação especial e a formação de professores proposta pelo programa "Educação inclusiva: direito à diversidade". Dissertação de Mestrado. UNIOSTE PR, Cascavel, 2011.

MAZZEU, Lidiane Teixeira Brasil. A política educacional e a formação de professores. Reflexões sobre os fundamentos teóricos e epistemológicos da reforma. In: MARSIGLIA, Ana Carolina Galvão (Org). Pedagogia Histórico-Crítica: 30 anos. Campinas: Autores Associados, 2011. (Coleção Memória da Educação).

MENDES, Enicéia Gonçalves. Deficiência mental: a construção científica de um conceito e a realidade educacional. Tese de Doutorado. Universidade de São Paulo. São Paulo, 1995.

NAGEL, Lizia Helena. Para que servem os cursos de formação de professores? Disponível em: <www.diaadiaeducacao.pr.gov.br> Acesso em: 13 de jul de 2014.

PARANÁ/UENP. Projeto pedagógico do curso de pedagogia. Cornélio Procópio, PR. 2011.

\section{RESOLUÇÃO CNE/CEB Nº 2, DE 11 DE SETEMBRO DE 2001. Institui Diretrizes}

Nacionais para a Educação Especial na Educação Básica. Disponível em:

<portal.mec.gov.br/cne/arquivos/pdf/CEB0201.pdf> acesso em: 10 ago 2014

RODRIGUES, David. Desenvolver a Educação Inclusiva: Dimensões do desenvolvimento profissional.: Revista Educação Especial, Brasília, Brasília Inclusão: v.4, n.2, p.7-16, jul./out.2008.

SAVIANI, Dermeval. A pedagogia no Brasil: história e teoria. Campinas, São Paulo: Autores Associados, 2008. (Coleção Memória da Educação).

Escola e democracia. São Paulo: Cortez, 1984.

. Pedagogia histórico-critica: primeiras aproximações. 10. ed. Campinas, SP: Autores Associados, 2008.

TOLEDO, Elizabete Humai de. Formação de professores em serviço por meio de pesquisa colaborativa visando à inclusão de alunos com deficiência. Dissertação de Mestrado. Universidade Estadual de Londrina, Londrina 2011.

UNESCO. Declaração Universal Dos Direitos Humanos. Brasília, 1948.

Declaração mundial sobre educação para todos: satisfação das necessidades básicas de aprendizagem Jomtien, 1990. UNESCO 1998. Disponível em:

<http://unesdoc.unesco.org/images/0008/000862/086291por.pdf >. Acesso em: 10 ago. 2014 
UNESCO. Declaração de Salamanca. Linha de ação sobre necessidades educativas especiais. Brasília: CORDE, 1994. Disponível em:

<http://portal.mec.gov.br/seesp/arquivos/pdf/salamanca.pdf>. Acesso em: 10 ago. 2014

Declaração da Guatemala. Convenção da Organização dos Estados Americanos, 1999. Disponível em: < http://www.planalto.gov.br/ccivil_03/decreto/2001/D3956.htm>. Acesso em: 10 ago. 2012.

VERONESE, Rafaela Júlia Batista; DAMASCENO, Benito Pereira; FERNANDES,Yvens Barbosa. Funções Psicológicas Superiores: Origem Social e Natureza Mediada. Revista Ciências Médicas, Campinas: PUC, nov/dez, 2005. 